\title{
How Bad Can It Be? The Relationship between GDP Growth and the Unemployment Rate
}

\author{
YiLi Chien, Research Officer and Economist
}

ities and regions across the U.S. are currently shut down due to the COVID-19 outbreak. Many states have already issued, or are considering issuing, stayat-home orders, under which most non-essential businesses must close and people are urged to stay home. These orders are meant to slow down or stop the spread of COVID-19 by limiting contact between persons and thus reducing opportunities for exposure and infection. With the closing of most non-essential businesses, the output of the U.S. economy will drop significantly and the unemployment rate will increase dramatically. Jobless claims are already flooding in across the U.S. ${ }^{1}$

\section{Sectors most likely to be heavily impacted by the COVID-19 pandemic amount to 70 percent of GDP.}

How bad can it be? We have seen several skyrocketing estimates of negative gross domestic product (GDP) growth rates and unemployment rates. One of the newest estimates is from Goldman Sachs, which is revising downward the GDP growth rate from -24 percent to -34 percent, with an unemployment rate of 15 percent. $^{2}$ These numbers are unprecedented, and hence it is not easy to impose discipline on them according to past experience.

This essay intends to find a relationship between GDP growth rates and unemployment rates by combining data from the Bureau of Labor Statistics (BLS) and Bureau of Economic Analysis (BEA). The employment requirement table from the BLS provides a detailed estimate of the number of employees required for $\$ 1$ million of output produced by each industry or sector. In addition, the BEA provides the GDP decomposition across different sectors and industries. So we can use the BLS's employment table together with the BEA's industry-level GDP to calculate a relationship between the GDP growth rate and unemployment rates. This calculation is based on GDP in the second quarter of 2019.

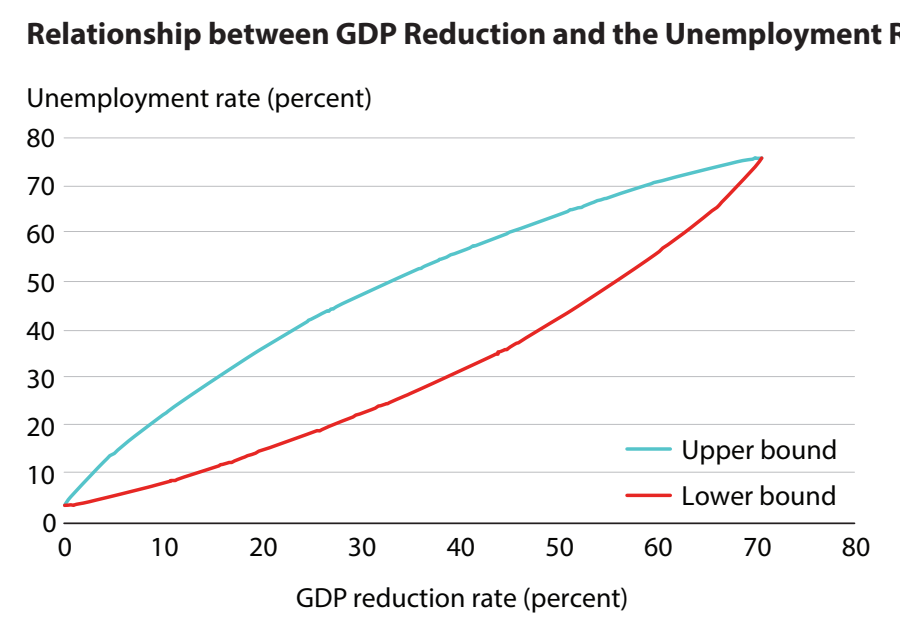

SOURCE: Bureau of Labor Statistics, Bureau of Economic Analysis, and author's calculations.

Some industries and sectors are relatively unaffected by the economy's shutdown. Let's assume these sectors' outputs remain unchanged from their levels in 2019. These sectors include farming, government, housing, hospitals, and food stores (such as supermarkets). The GDP for these sectors accounts for 30 percent of total U.S. GDP.

In addition, some sectors are more labor-intensive than others, meaning that the labor requirement of some sectors is higher than that of others to produce the same amount of output. Hence, the unemployment rate is higher (lower) if the GDP reduction comes from more (less) labor-intensive sectors. Hence, as indicated by the figure, there are upperbound (blue line) and lower-bound (red line) estimates of unemployment rates conditional on the reduction of the GDP growth rate. The upper bound assumes that the GDP reduction (shown on the $x$-axis) progresses from the most labor-intensive to the least labor-intensive sectors. The lower bound assumes the opposite.

Given the unemployment rate for the second quarter of 2019 was around 3.6 percent, both lines start with unemployment rates at 3.6 percent, assuming that GDP is unchanged from its level in 2019. If we lost all output from these impacted sectors (up to 70 percent of GDP), then the unemployment rate would dramatically increase 


\section{ECONOMIC Synopses}

to 76 percent. According to this calculation, the unemployment rate estimate of Goldman Sachs seems to be low if the GDP growth rate is -34 percent. More specifically, the unemployment rate should range between 26 percent and 51 percent for a 34 percent reduction in GDP.

My calculation intends to impose some discipline on the wild estimates of upcoming GDP and unemployment rates. Obviously, my calculation has several caveats. First, it is based on the assumption that some sectors are totally unchanged, which account for 30 percent of GDP. It could be argued that employment or output of some businesses (e.g., grocery stores or Amazon) could be higher in response to the economic shutdown. In addition, there are many factors that could alter this rough calculation and potentially bring down the unemployment rate. It is highly possible that the unemployment rate could respond slowly to the rapid decline of GDP because employers anticipate a faster recovery in the third quarter and do not wish to lose their workers. However, the extension of unemployment insurance benefits (as passed by Congress) could encourage layoffs and raise the unemployment rate.

\section{Notes}

${ }^{1}$ Morath, E.; Hilsenrath, J. and Chaney, S. "Record Rise in Unemployment Claims Halts Historic Run of Job Growth." Wall Street Journal, updated March 26, 2020; https://www.wsj.com/articles/the-long-run-of-american-jobgrowth-has-ended-11585215000.

2 Cox, J. "Goldman Sees 15 percent Jobless Rate and 34 percent GDP Decline, Followed By the Fastest Recovery in History." CNBC, updated April 1, 2020; https://www.cnbc.com/2020/03/31/coronavirus-update-goldman-sees-15percent-jobless-rate-followed-by-record-rebound.html. 